\title{
ATTACHMENT AS A PREDICTOR OF UNIVERSITY ADJUSTMENT AMONG FRESHMEN: EVIDENCE FROM A MALAYSIAN PUBLIC UNIVERSITY
}

\author{
${ }^{1}$ Walton Wider, ${ }^{2}$ Mazni Mustapha, \\ ${ }^{3}$ Murnizam Halik \& ${ }^{4}$ Ferlis Bahari \\ ${ }^{I}$ Faculty of Arts and Social Science \\ Universiti Tunku Abdul Rahman, Malaysia \\ ${ }^{2-3}$ Faculty of Psychology and Education \\ Universiti Malaysia Sabah, Malaysia \\ ${ }^{4}$ Psychology and Social Health Research Unit \\ Universiti Malaysia Sabah, Malaysia
}

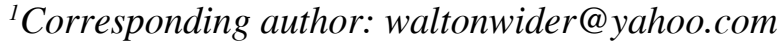

\begin{abstract}
Purpose - Building upon attachment theory and emerging theory, the current study was aimed at examining the effect of peer attachment in predicting adjustment to life in university among freshmen in a public unirvsity in East Malaysia. Furthermore, it sought to examine the influence of gender and perceived-adult status as moderators of the relationship between student attachment and student adjustment.

Methodology - Data was collected from 557 freshmen in one of the public universities in East Malaysia. Two questionnaires, namely The Inventory of Parent and Peers Attachment (IPPA) and The Student Adaptation to College Questionnaire (SACQ) were used in this study. Partial Least Square (PLS) analysis was employed to examine the hypothesized relationships.

Findings - The findings of the study showed that peer trust positively influenced academic and social adjustment. Meanwhile, peer communication positively influenced social adjustment, but negatively influenced personal-emotional adjustment. Lastly, peer alienation negatively influenced personal-emotional adjustment, but positively influenced institutional attachment. The Partial Least
\end{abstract}


Square - Multi Group Analysis (PLS-MGA) results indicated no significant differences in peer attachment and university adjustment across gender and perceived-adult status.

Significance - The findings of this study has empirically proven the link between attachment theory and emerging adulthood theory, providing further corroborative evidence for the argument put forth by Howes and Spieker (2008) on the alternate attachment bond during emerging adulthood period. In terms of practical benefits,, several parties who work with emerging adult clients in the Malaysian university setting will be able to benefit from the research findings, particularly counsellors and academicians.

Keywords: Emerging adulthood, peer attachment, university adjustment, gender, perceived adult status.

\section{INTRODUCTION}

Admission to university is an important test of a person's capability of adjusting oneself to a new environment (Dyson \& Renk, 2006). The first year of university life is perceived as the most challenging throughout the study period of a student (Feldt, Melody, \& Dew, 2011). This period is associated with a greater change in physical, emotional, moral, social, and intellectual aspects (Bakar \& Mohamed, 2004). The new environment in the university shapes the perception of the freshmen, especially about their ability to overcome the obstacles and challenges of their university life (Siah \& Tan, 2015). If the freshman is unable to conquer the challenges and obstacles accordingly, it will lead to various problems and issues, especially psychological problems (Bakar, Mohamed, Abdullah, \& Yusof, 2015).

Many studies have been conducted on the problems encountered by freshmen (see Holt, 2014; Nakayama, Nakanishi, Nagahama, \& Nakajima, 2015; Goodboy, Martin, \& Goldman, 2015; Abdullah, Kong, \& Talib, 2014; Yang \& Brown, 2016). Researchers agreed that university adjustment consists of various complex phenomena (Baker \& Siryk, 1986). Past studies have consistently reported that students who were able to accustom themselves to their university life are often able to attain good academic achievement, experienced 
less social problems, and suffered less depression (Dyson \& Renk, 2006; Lapsley \& Edgerton, 2002); exhibited good locus of control and were assertive (Karahan, Sardoğan, Özkamali, \& Dicle, 2005); had higher self-esteem (Pancer, Hunsberger, Pratt, \& Alisat, 2000), enjoyed better social support (Abdullah et al., 2014; Dyson \& Renk, 2006); gained higher self-efficacy (Torres \& Solberg, 2001), possessed good coping skills (Dyson \& Renk, 2006), showed optimism (Yalim, 2007), learned good time management, goal orientation, and self-advocacy (Byrd \& Macdonald, 2005), and acquired higher emotional intelligence (Ciarrochi \& Scott, 2006).

In 2013, the Ministry of Education, Malaysia developed the Malaysia Education Blueprint 2015-2025 (Higher Education) or MEB (HE). The new blueprint was developed to make constructive changes and transform the academic and social landscape of higher education in Malaysia, as well as to ensure that Malaysia would be able to compete effectively on the global stage. The higher education transformation under the MEB (HE) has triggered awareness of the need for the various stakeholders in its higher education indtitutions to ensure that university students are able to prepare themselves for the demands and challenges of life in the university. As there has been an uphill trend in the number of students enrolling in universities every year, there is a need to study the ability of the students to be well prepared upon embarking on their tertiary education (Davis, 2012).

The enrolment of undergraduates in Malaysian universities is rising year by year (Ariffin, Ahmad, Ahmad, \& Ibrahim, 2008). From 2003 until 2013, the total undergraduate enrolment in the universities increased by $60.4 \%$ (Ministry of Education, Malaysia, 2013). Specifically, undergraduate enrolment in public universities increased by $39.5 \%$. The clear implication from the huge numbers of undergraduates aged between 19 to 24 years old eligible to further their studies in higher education institutions is that, there is an urgent need to study issues related to their adjustments to university life.. Freshmen often experience a challenging period when they transition to life in the university.

These freshmen will certainly encounter various problems when adjusting to life as undergraduates in the university. Research conducted in Malaysia reported difficulties faced in the following 
areas: course registration, comprehending English texts, inability to attend early morning lectures, health problems, financial constraints, family problems and lack of sleep (Ahmad, Fauziah, Azemi, Shaari, \& Zailani, 2002; Redhwan, Sami, Karim, Chan, \& Zaleha, 2009). Other than that, Dixon and Kurpius (2008) reported that students were unable to adjust to life in the university was because of their separation from family and the increased student workload. Friedlander, Reid, Shupak and Cribbie (2007) reported that changes in the students'relationship with their parents, peers, and romantic partners can affect student adjustments to life in the university. Many students withdrew from the university during the first two years of studies, and the majority of them perceived the difficult transition to life as a student in the university as the main cause of their ability to continue with their studies (Yazedjian, Toews, \& Navarro, 2009).

Due to the increasing number of student withdrawals from their university studies, the Ministry of Education, Malaysia has implemented various programs to tackle this problem (Abdullah, Elias, Mahyuddin, \& Uli, 2009). It is the priority of the university to provide sufficient services and facilities in order to facilitate adjustment among university freshmen (Davis, 2012). Although the effort has been long undertaken by the Ministry, the issue of student adjustment, especially among first year students remains a serious problem in Malaysia. As highlighted in a speech by the Universiti Putra Malaysia's Deputy Vice Chancellor of Student Affairs and Alumni, Professor Datuk Dr. Mohammad Shatar Sabran in the Mymetro (September, 2015, translated from the Malay language), "transition from high school to higher education is a difficult experience for many university freshmen. This situation causes them to faces adjustment problem in the campus. Besides this group often face personal and interpersonal challenges with the environmental demands."

Factors that influenced first-year student adjustments to university life are complex (Wang, Chen, Zhao \& Xu 2006). A critical question often arises: "how does a first year student transition to life as an undergraduate in the university?" Therefore, the present study was aimed at examining the link between attachment and university adjustment, more specifically to examine whether peer attachment would influence the adjustments made by first year students during 
the transition period at the university. Even though studies on adolescents have received increasing attention in Malaysia, studies in identifying attachment relationships between adolescents are still lacking (Ishak, Yunus, \& Iskandar, 2010). In addition, the majority of researches related to adolescent attachment that has been documented thus far is based on population samples from western countries, and there are only a few published research studies which are related to non-western samples, such as those from Malaysia (Zulkefly \& Wilkinson, 2014). The present study is important as it has provided empirical evidence of the relationship between peer attachment and adjustment to life in the university from an Asian perspective. In terms of practical benefits accruing from the study, it is posited that university counsellors can take advantage of the findings from this study as these findings will provide them with a deeper understanding of and better insights into the factors which relate to freshmen adjustments to life in the university.

\section{Background Theory}

There are various ways to identify student difficulties in adjusting to university life; nevertheless, most of the literature on university adjustment supported the use of multiple indicators to examine adjustment at the same time so that the overview of adjustment can be identified (Tinto, 1996). The three theories of student development that have been widely used in the literature are theory of identity development (Chickering, 1969), retention theory (Tinto, 1987) and model of undergraduate socialization (Weidman, 1989) (Wintre \& Yaffe, 2000).

In Chickering (1969), the main focus was on understanding student development in terms of their identity development, that is their progression through seven different vectors of development (developing competence, managing emotions, moving through autonomy toward interdependence, developing mature interpersonal relationships, establishing identity, developing purpose, and developing integrity). Tinto (1987) proposed six constructs in his theoretical framework, which he claimed was able to explain the student's experience during the transition from school/family environment to the university environment. His theory was underpinned by the perceived student need for independence. The six 
constructs of the theory were related to pre-entry attributions, goals/ commitments (which were divided into two: student's aspiration and institutional goals, intention and external commitments), institutional experiences, integration, and outcome (Waller, 2009). In contrast, Weidman's (1989) model of socialization was the first theory that incorporated parent-child relationships as predictors of adjustment in the university (Wintre \& Yaffe, 2000).

Although all the aforementioned theories had been empirically tested, none of them offered a conceptual framework that linked attachment constructs with university adjustment (Wintre \& Yaffe, 2000). Therefore, the present study was aimed at linking both attachment theory and emerging adulthood theory in order to explain the relationship between attachment and student adjustment at the university level.

\section{Linking Attachment Theory and Emerging Adulthood Theory}

Attachment theory postulated that healthy exploration behaviour started from a secure base, which developed from the relationship between the infant and caregiver (parents), whereby parents served to provide protection and a sense of security (Ainsworth, Blehar, Waters, \& Wall, 1978). During infancy and childhood, attachment was examined by assessing the separation behaviour and reunion towards caregivers (Ainsworth et al., 1978). However, attachment among emerging adults was examined by looking at the cognitiveaffective dimension, which was seen as related to the following three components, namely mutual trust, communication quality, and level of alienation (Armsden \& Greenberg, 1987). The relationship with parents would remain important from childhood to adulthood (Selby, 2001), therefore, development task, such as identity exploration was also influenced by parental attachment (Beyers \& Goossens, 2008; Bloom, 1980). Meanwhile, the emerging adulthood (EA) theory provided a framework that looked at the transition to adulthood at the present time as a prolonged period, and no longer to be perceived as a transition, but as a distinct period in a human life trajectory (Arnett, 2007). EA was the period between adolescence and adulthood and ranged between 18 and 25 years old. It would be characterized by five unique dimensions, which were identity exploration, possibilities/ experimentation, negativity/instability, self-focused, and feeling inbetween. Arnett (2014) asserted that the majority of emerging adults 
were currently pursuing their studies in higher education. The higher education context was an example in which emerging adults were faced with the challenges and opportunities in the developmental aspects (Rarick, 2011). Most of the studies asserted that the indicator of well-being among emerging adult was actually increasing as the outcome of the entry into an institution such as transition to the university (Schulenberg \& Zarrett, 2006). The development period while at the university could promote experiences such as ample opportunities in exploring cognitive, social, and psychological development aspects that could influence student learning, social activities, and interaction with others (Montgomery \& Côté, 2003). Although the EA period was marked as moving towards selfsufficiency and independence (Tanner, 2006), emerging adults were still characterized as a continued dependence on the parent (Arnett, 2000). Studies have proven that the relationship between emerging adults and parents has remained strong (Diamond, Fagundes \& Butterworth, 2010). Through a review of past studies, it has been noted that emerging adulthood theory (Arnett, 2014) can be applied and extended to the existing attachment theory (Bowlby, 1969). Through a developmental view, Howes \& Spieker (2008) postulated that emerging adulthood theory and attachment theory converged in that both theories claimed there existed an alternate attachment bond during the emerging adulthood period. Moreover, the attachment framework has played an important role in the study of the cognitive, social, and emotional adjustment of young people (Gorrese, 2015).

Thus, to test the conceptual framework linking attachment theory and emerging adulthood theory, this study proposed a research framework linking the peer attachment variable and the adjustment to university variable. Three components (trust, communication, and alienation) of peer attachment by Armsden \& Greenberg (1987) were used. According to Mattanah, Lopez, \& Govern (2011), and Armsden \& Greenberg (1987) it would be appropriate to measure the emerging adult's perception of the attachment relationship with peers. Meanwhile, Baker \& Siryk's (1989) four components (academic, social, personal-emotion, and institutional attachment) of adjustment to university construct were also used. The use of the four components in Baker \& Syirk (1989) was deemed appropriate due to its suitability in measuring adjustment, particularly among freshmen (Feldt et al., 2011). 


\section{Research Model and Hypothesis}

Adjustment to university. Adjustment is a process whereby an individual is adjusting to the new environment by dealing with the pressures caused by the demands of the new environment (Abdullah, Elias, Mahyuddin, \& Ulli, 2009). To date, the majority of studies on university adjustment have agreed that the student's overall adjustment is related to the following four domains: academic, social, personal-emotion, and institutional attachment (Lenz, 2014). These domains can be examined using the Student Adjustment to College Questionnaire (SACQ) by Baker \& Siryk (1989). The SACQ is a reliable measure of student adjustment to life at the university, as well as comprehending the transition experience of the freshman (Feldt, Melody, \& Dew, 2011). Recent studies such as SmojverAžić, Dorčić, \& Živčić-Bećirević (2015); Melendez (2015); Ramler, Tennison, Lynch, \& Murphy (2015); and Lenz (2014) had used the SACQ in examining first year student adjustment to life in the university.

In the current study, the focus was on the four aspects of academic adjustment identified by Baker \& Siryk (1989), and they were as follows: (i) motivated to be at university and doing assignments; (ii) real motivation to strive academically; (iii) the effectiveness and success of the efforts exerted; and (iv) satisfaction towards the academic environment in the university. The academic situation in the university is different than the academic situation in the high school. For the majority of the students, the transition to the university requires them to adjust in terms of practice and academic needs. Many undergo major changes in several aspects, such as the number of students in a class, the self-managed class/lecture schedule, the flexible and short study hours, the open relationship with lecturers, the high personal responsibility, the high expectations from out-ofclassroom activities, and other workloads.

Academic adjustment has been defined as the extent to which the first year student was able to deal with the learning demand, such as the motivation to complete the academic requirements, the efforts to seek knowledge and student satisfaction in an academic environment (Friedlander, Reid, Shupak, \& Cribbie, 2007). This definition clearly 
indicates that academic adjustment is a broad concept that involves real academic performance among students, and several other factors related to the ability of the students in dealing with academic demands in the university such as motivation and satisfaction in an academic setting.

Baker and Siryk (1989) identified social adjustment as the level and success in social activity participation as well as general performance; participation with others in the university; moving out from home and the importance of the people at home; and the satisfaction of the social setting in the university. Social adjustment in the university is defined as processes by which students integrate themselves into the campus community, develop a support system, and develop a negotiation towards the new emerged freedom in the university life (Gerdes \& Mallinckrodt, 1994). During the transition period, the freshmen deal with personal challenges and new interpersonal skills, which involve the need to develop new relationships, new learning skills and modify the existing relationship towards parents and family members (Parker, Summerfeldt, Hogan, \& Majeski, 2004). The experience of moving out of the home for the first time, being separated from the family and living far from parents, represents autonomy for freshmen (Gray, Vitak, Easton, \& Ellison, 2013). This experience therefore, requires them to be independent in dealing with the new interpersonal demands of life in the university.

The conception of personal-emotional adjustment is based on two aspects, and these are psychological well-being and physical wellbeing (Baker \& Siryk, 1989). It is related to the extent students deal with general psychological stress or somatic effects resulting from stress (Baker \& Siryk, 1984). University life challenges the students both academically and socially, and also affects the students'developmental aspect. In terms of the personal-emotional aspects, adjustment is related to the level of stress, depression or physical reaction. In addition, Erikson (1963) postulated that first year students often struggled to adjust to the new environment because during this period, they were actively forming an identity; the issues that students often had to contend with were related to gender, sexual orientation, race, cultural background, and ethnic origins. 
Finally, Baker \& Siryk (1989) have raised an important issue of concern which would be useful to this study. They postulated that institutional attachment was the commitment towards experience at the university and this could be explained by the following two aspects, namely the students' general satisfaction while at university and their satisfaction towards the university. Institutional attachment was referred to as the level of a student's commitment in obtaining a degree, as well as the power of attachment towards the university (Bakers \& Siryk, 1989; Pascarella \& Terenzini, 1980; Eimers \& Pike, 1997). Among the general factors identified were the students' feeling towards decisions to attend university, and their thoughts on postponing or dropping out of their studies.

Peer attachment. Mohamed (2012) has argued that most of the literature on attachment and university adjustment was focused on parental attachment (see Hiester, Nordstrom, \& Swenson, 2009; Selby, 2001; Love, Tyler, Thomas, Garriott, Brown, \& Roan-Belle, 2009; Sarigiani, Trumbell, \& Camarena, 2013). Although research on peer attachment is still lacking, the review of previous literature has clearly supported the view that a positive relationship with peers is linked to healthy adjustment among adolescents (Laible, Carlo, \& Raffaelli, 2000). Furthermore, a romantic relationship is a better target for intervention than parental attachment (Lapsley \& Edgerton, 2002). The study by Lapsley, Rice, \& FitzGerald (1990) was the first empirical study that examined the influence of peer attachment towards university adjustment. The authors reported that peer attachment was significantly related to academic and personalemotional adjustment among freshmen. Meanwhile, Selby (2001) reported that only male freshmen showed a positive relationship between peer attachment and university adjustment. A thorough search of the various databases (Google Scholar, ProQuest, JSTOR, ERIC, EBSCO Host, PsycInfo), did not find any latest research studies on the relationship between peer attachment and university adjustment. As a matter of fact, there was no research conducted which linked the three sub-scales (trust, communication, alienation) of peer attachment by Armsden \& Greenberg (1987) and the four sub-scales (academic, social, personal-emotion, institutional attachment) of university adjustment by Baker \& Siryk (1989). 
The network of attachments starting from adolescence has been widening and, therefore would not be focused merely among family members (Wilkinson, 2006; Gorrese \& Ruggieri, 2012), even though initial attention was given to attachment to parents. Nevertheless, numerous studies have pointed out that the relationship with peers was also vital in the life of emerging adulthood (Doherty \& Feeney, 2004; Collins \& van Dulmen, 2006; Schnyders, 2012). Furthermore, attachment needs were often with peers or with a romantic partner, and was no longer with the premier caregiver, that is, one's parents (Mayselessx, 2004). Erikson (1968) also asserted that developing a strong relationship with peers or a romantic partner was the main marker during the emerging adulthood period. Therefore, from the arguments presented in the foregoing discussions, the aim of the current study was to examine the influence of peer attachment on university adjustment among freshmen in public universities. The hypotheses below were assumed in this study:

H1: Trust is positively related to academic adjustment.

$\mathrm{H} 2$ : Trust is positively related to social adjustment.

H3: Trust is positively related to personal-emotional adjustment.

H4 Trust is positively related to institutional attachment.

H5: Communication is positively related to academic adjustment.

H6: Communication is positively related to social adjustment.

H7: Communication is positively related to personal-emotional adjustment.

H8: Communication is positively related to institutional attachment.

H9: Alienation is negatively related to academic adjustment.

H10: Alienation is negatively related to social adjustment.

H11: Alienation is negatively related to personal-emotional adjustment.

H12: Alienation is negatively related to institutional attachment.

Gender. Past research reported mixed findings for the variable of gender in relation to adjustment to life in university. A number of studies reported a gender difference in adjustment to life in university; more specifically, the general finding was that females had more problems in adjusting (Kenny \& Donaldson, 1991; Tinajero, Martínez-López, Rodríguez, Guisande, \& Páramo, 2014). Although female students were seen as having less inclination towards adjusting socially and emotionally than the male students, 
they nevertheless, showed better adjustment in terms of academic matters than their male counterparts (Duchesne, Ratelle, Larose, \& Guay, 2007; Weckwerth \& Flynn 2006; Wintre \& Yaffe, 2000; Abdullah et al., 2009). However, there were some studies which also reported no gender difference in student adjustment to life in university (Sümer, Poyrazli, Grahame, 2008; OTLU, 2010). To date, only one study examined the moderating effect of gender on the relationship between attachment and adjustment to life in university, in the context of parents, and none in terms of peer context. Schultheiss \& Blustein (1994) found that female students are more likely to benefit from an attachment relationship with parents in their adjustment to life in the university. Another study that used gender as the moderator in assessing university adjustment was carried out by Janković, Nikolić, Vukonjanski, \& Terek (2016). In light of the gender issues discussed, the present study has proposed H13 below.

H13: There is a gender difference in the relationship between peer attachment and adjustment to life in university.

Perceived adult status. Although Arnett (2000) postulated that the majority of the emerging adults did not feel they had achieved adulthood, a small number of them held the opposite view. When Arnett (2003) probed into the issue by asking "Do you feel that you have reached adulthood?", $50 \%$ of the respondents indicated that "in some respects 'yes', and in some respects 'no' ", whereas $46 \%$ indicated "no" and only 4\% indicated "yes". Several studies which replicated Arnett's (2003) study found that a handful of respondents perceived that they had already achieved adulthood, thus validating the argument by Arnett (2003) (cf. Rarick, 2011; Nelson, xing Duan, Padilla-Walker, \& Luster, 2012; Meckelmann, Peiker, \& Potsdam, 2013). Furthermore, Wider, Halik, Mustapha \& Bahari (2015) conducted a preliminary analysis of emerging adulthood experiences among second year students in Malaysia and reported that $66.7 \%$ indicated "in some respects 'yes', and in some respects 'no". The responses, "in some respects 'yes', and in some respects 'no", and "no" were grouped into a category labelled "non-perceived adult status"; whereas the response "yes" was grouped into the "selfperceived adult status" (Arnett, 2003). 
Although the latter group was perceived as a minority and unique, there were only a few studies conducted in order to understand how emerging adults with self-perceived adult status was distinct from other emerging adults (Rarick, 2011). It is worthy to examine whether emerging adults with self-perceived adult status have more advantages compared to other emerging adults, as past studies have reported mixed findings. For example, Nelson (2009) found that emerging adults with self-perceived adult status were engaged in higher identity development, but this contradicted the findings in Nolan (2006). Meanwhile, Nelson \& Barry (2005) found that selfperceived adults had experienced lower incidence of depression, but this finding contradicted the finding in Rarick (2011). Other studies have found that self-perceived adult also engaged in fewer deviant behaviours such as substance use and drunk driving (Nelson \& Barry, 2005; Blinn-Pike, Worthy, Jonkman, \& Smith, 2008); had higher self-esteem (Nolan, 2006); were more independent and more successful in academic studies, and were more committed in a long term relationship (Rarick, 2011). In light of these contradictory findings in past studies, there is a need to explore further the predictive factor of adult status towards other psychosocial aspects. The foregoing review of the literature on emerging adulthood has shown that emerging adults exhibited differences in terms of behaviour, beliefs, and attitudes and such a predictive factor study will be able to contribute in some respects to the emerging adulthood theory. In light of the emergent adulthood issues discussed, the present study has proposed $\mathrm{H} 14$ below.

H14: There is a difference in how self-perceived adults status and non-perceived adult status affect the relationship between peer attachment and adjustment to life in university.

\section{METHODOLOGY}

\section{Sampling and Data Collection}

The respondents for this study were university freshmen in a public university in East Malaysia. To determine the sample size of the respondents, the Gpower software was used to calculate the 
minimum sample size required in this study. The research model showed a maximum of three predictors, a medium (0.15) effect size was chosen and the power needed was 0.95 . A minimum sample size that was required in this study was 119. A convenience sampling method was employed, whereby responses were gathered from 557 first year undergraduates from different faculties in the public university.

\section{Measures}

A booklet questionnaire that consisted of several sections was developed. The respondents were asked to answer the sections regarding demographic characteristics, self-perceived adult status, their attachment to parents and peers, their current adjustment to life in university, and their perceptions of emerging adulthood experiences. However, in this study, only peer attachment and adjustment to life in university questionnaires were employed. The measures for both questionnaires were adapted from Armsden \& Greenberg (2009), and Baker \& Siyrk (1999) using a 5-point Likert scale $(1=$ almost never to $5=$ almost always $)$.

\section{Demographic Details of Respondents}

Table 1 displays the demographic profile of the respondents. The number of female respondents $(63.4 \%)$ were more than the number of males $(36.6 \%)$ and these figures reflected the same ratio of gender representation in the public universities in Malaysia. This research was conducted in East Malaysia, particularly in Sabah; therefore, the majority of the respondents were Bumiputera Sabah, i.e., native Sabahans (48.5\%). When the respondents were asked "Do you think you have reached adulthood?", the majority answered "in some respects 'yes', in some respects 'no"' (64.8\%). Approximately, $86.5 \%$ of the respondents were staying in a hostel provided by the university. 
Table 1

Demographic Details of Respondents

\begin{tabular}{lcc}
\hline Profile & Frequency & Percentage \\
\hline Gender & 204 & 36.6 \\
Male & 353 & 63.4 \\
Female & & \\
Ethnicity & 128 & 23.0 \\
Malay & 102 & 18.3 \\
Chinese & 10 & 1.8 \\
Indian & 270 & 48.5 \\
Bumiputera Sabah & 23 & 4.1 \\
Bumiputera Sarawak & 24 & 4.3 \\
Others & & \\
Do you think that you have reached & & \\
adulthood? & 145 & 26.0 \\
Yes & 51 & 9.2 \\
No & 361 & 64.8 \\
In some respect yes, in some respect no & & \\
Current living situation & 51 & 9.2 \\
Living with parents & 482 & 86.5 \\
Living in the hostel & 22 & 3.9 \\
Living in a rented-house & 2 & 0.4 \\
Others & & \\
\hline
\end{tabular}

\section{RESULTS}

A Partial Least Squares (PLS) analysis technique, using SmartPLS 2.0 software (Ringle, Wende, \& Will, 2005) was used to analyse the research model. By following the suggestion by Hair, Hult, Ringle, \& Sarstedt (2014), two-stage analytical procedures were performed. Firstly, the measurement model was tested by examining the validity and reliability of the measures, and then the structural model was examined by testing the hypothesized relationships.

\section{Measurement Model}

In order to examine the validity of the research model, two types of validity were tested, namely convergent validity and discriminant validity. Hair et al. (2014) indicated that the factor loadings and 
the average variance extracted (AVE) must be more than 0.5 and the composite reliability (CR) is 0.7 to be acceptable for convergent validity. As shown on Table 2, the loadings, AVE and CR for all construct are above the threshold value, thus confirming that convergent validity has been established.

Table 2

Results of the Measurement Model

\begin{tabular}{|c|c|c|c|c|}
\hline \multirow[t]{2}{*}{ Construct } & \multirow[t]{2}{*}{ Item } & \multicolumn{3}{|c|}{ Convergent Validity } \\
\hline & & $\begin{array}{c}\text { Factor } \\
\text { Loadings }\end{array}$ & AVE & $\begin{array}{l}\text { Composite } \\
\text { Reliability }\end{array}$ \\
\hline \multirow[t]{8}{*}{ Trust } & PE_TRUST10 & 0.819 & 0.618 & 0.928 \\
\hline & PE_TRUST2 & 0.826 & & \\
\hline & PE_TRUST3 & 0.841 & & \\
\hline & PE_TRUST4 & 0.766 & & \\
\hline & PE_TRUST5 & 0.797 & & \\
\hline & PE_TRUST6 & 0.765 & & \\
\hline & PE_TRUST7 & 0.731 & & \\
\hline & PE_TRUST9 & 0.735 & & \\
\hline \multirow[t]{5}{*}{ Communication } & PE_COMM1 & 0.801 & 0.606 & 0.884 \\
\hline & PE_COMM2 & 0.822 & & \\
\hline & PE_COMM3 & 0.811 & & \\
\hline & PE_COMM7 & 0.719 & & \\
\hline & PE_COMM8 & 0.731 & & \\
\hline \multirow[t]{4}{*}{ Alienation } & PE_ALI3 & 0.698 & 0.564 & 0.838 \\
\hline & PE_ALI4 & 0.767 & & \\
\hline & PE_ALI5 & 0.774 & & \\
\hline & PE_ALI7 & 0.761 & & \\
\hline \multirow[t]{5}{*}{ Academic } & ACAD17 & 0.712 & 0.520 & 0.844 \\
\hline & ACAD19 & 0.727 & & \\
\hline & ACAD2 & 0.747 & & \\
\hline & ACAD24 & 0.669 & & \\
\hline & ACAD7 & 0.736 & & \\
\hline
\end{tabular}




\begin{tabular}{|c|c|c|c|c|}
\hline \multirow[t]{2}{*}{ Construct } & \multirow[t]{2}{*}{ Item } & \multicolumn{3}{|c|}{ Convergent Validity } \\
\hline & & $\begin{array}{c}\text { Factor } \\
\text { Loadings }\end{array}$ & AVE & $\begin{array}{l}\text { Composite } \\
\text { Reliability }\end{array}$ \\
\hline \multirow[t]{4}{*}{ Social } & SOC1 & 0.723 & 0.512 & 0.808 \\
\hline & SOC19 & 0.730 & & \\
\hline & SOC20 & 0.703 & & \\
\hline & SOC4 & 0.707 & & \\
\hline \multirow[t]{5}{*}{ Personal-Emotion } & PEMO10 & 0.727 & 0.519 & 0.843 \\
\hline & PEMO12 & 0.688 & & \\
\hline & PEMO15 & 0.696 & & \\
\hline & PEMO2 & 0.678 & & \\
\hline & PEMO5 & 0.806 & & \\
\hline \multirow[t]{4}{*}{ Institutional Attachment } & INS2 & 0.616 & 0.599 & 0.855 \\
\hline & INS4 & 0.847 & & \\
\hline & INS5 & 0.849 & & \\
\hline & INS6 & 0.762 & & \\
\hline
\end{tabular}

Note. PE_TRUST1, PE_TRUST8, PE_TRUST1, PE_COMM4, PE_COMM5, PE_ COMM6, PE_ALI1, PE_ALI2, PE_ALI6, ACAD1, ACAD3, ACAD4, ACAD5, ACAD6, ACAD8, ACAD9, ACAD10, ACAD11, ACAD12, ACAD13, ACAD14, ACAD15, ACAD16, ACAD18, ACAD20, ACAD21, ACAD22, ACAD23, SOC2, SOC3, SOC5, SOC6, SOC7, SOC8, SOC9, SOC10, SOC11, SOC12, SOC13, SOC14, SOC15, SOC16, SOC17, SOC18, PEMO1, PEMO3, PEMO4, PEMO6, PEMO7, PEMO8, PEMO9, PEMO11, PEMO13, PEMO14, INS1 and INS3 were deleted due to low factor loadings.

The next step is to examine the discriminant validity, i.e., the extent to which items are differentiated among constructs or measure distinct concepts. To determine the discriminant validity, the measure is tested by following Fornell \& Larcker's (1981) criterion which is comparing the square root of the AVE against the correlations of the other constructs. Discriminant validity is indicated if the AVE extracted is larger than its correlations with other constructs. Table 3 shows the square root of the AVE represented by the diagonal figures (in bold) that demonstrate higher values than the equivalent row and column values. Thus, all constructs are found to be distinct from each other. Overall, the current research model has an acceptable convergent and discriminant validity. 
Table 3

Discriminant Validity

\begin{tabular}{cccccccc}
\hline & ACA & ALI & COM & INA & PEM & SOC & TRU \\
\hline ACA & $\mathbf{0 . 7 2 1}$ & & & & & & \\
ALI & -0.150 & $\mathbf{0 . 7 5 1}$ & & & & & \\
COM & 0.371 & -0.238 & $\mathbf{0 . 7 7 8}$ & & & & \\
INA & -0.219 & 0.412 & -0.057 & $\mathbf{0 . 7 7 4}$ & & & \\
PEM & 0.056 & -0.320 & -0.085 & -0.375 & $\mathbf{0 . 7 2 0}$ & & \\
SOC & 0.644 & -0.210 & 0.432 & -0.199 & 0.091 & $\mathbf{0 . 7 1 6}$ & \\
TRU & 0.380 & -0.403 & 0.775 & -0.187 & 0.064 & 0.437 & $\mathbf{0 . 7 8 6}$ \\
\hline
\end{tabular}

Note. Diagonals (in bold) represent the square root of the average variance extracted while the off-diagonals are correlations among constructs.

$\mathrm{ACA}=$ Academic; $\mathrm{ALI}=$ Alienation; $\mathrm{COM}=$ Communication; $\mathrm{INA}=$ Institutional Attachment; PEM=Personal Emotion; $\mathrm{SOC}=$ Social; TRU=Trust

\section{Structural Model}

According to Hair et al. (2014), the assessment of structural model involves examining the $\mathrm{R}^{2}$, beta and $\mathrm{t}$-values. This study employed a bootstrapping procedure using 500 resamples. Other than that, Hair et al. (2014) also suggested reporting the predictive relevance $\left(\mathrm{Q}^{2}\right)$ and the effect size $\left(\mathrm{f}^{2}\right)$.

Firstly, all path estimates were examined to indicate whether the hypothesized relationships were significant or otherwise. Referring to Table 4, Trust $(\beta=0.225, \mathrm{p}<0.01)$ and Communication $(\beta=0.0 .194$, $\mathrm{p}<0.01$ ) both positively influenced Academic Adjustment, explaining $15.9 \%$ of the variance in Academic Adjustment. Trust $(\beta=0.223$, $\mathrm{p}<0.01)$ and Communication $(\beta=0.244, \mathrm{p}<0.01)$ both positively influenced Social Adjustment, explaining 21.6\% of the variance in Social Adjustment. Meanwhile, Trust $(\beta=0.146, \mathrm{p}<0.05)$ positively influenced Personal-emotion Adjustment; whereas, Communication $(\beta=-0.308, \mathrm{p}<0.01)$ and Alienation $(\beta=-0.326, \mathrm{p}<0.01)$ negatively influenced Personal-emotion Adjustment, explaining 13.7\% of the variance in Personal-emotion Adjustment. Lastly, Trust $(\beta=-0.144$, $\mathrm{p}<0.01)$ negatively influenced Institutional Attachment; whereas Communication $(\beta=0.147, \mathrm{p}<0.01)$ and Alienation $(\beta=0.389$, 
$\mathrm{p}<0.01)$ positively influenced Institutional Attachment, explaining $17.9 \%$ of the variance in Institutional Attachment. The values of all $\mathrm{R}^{2}$ were above 0.13 thus exhibiting a substantial model according to Cohen (1988).

According to Sullivan and Feinn (2012), reporting only the significant $p$ value for an analysis is not adequate, especially if the sample size is big. Both the substantive significance (effect size) and statistical significance ( $p$ value) need to be reported. Therefore, the hypothesized relationship in this study is supported if both the $p$ value and effect sizes show an acceptable estimation. By following the suggestion by Hair et al. (2014) on assessing the effect sizes, the change in $\mathrm{R}^{2}$ value was examined. The $\mathrm{R}^{2}$ change was examined by omitting a specified exogenous construct of the model to examine whether the omitted constructed had an essential impact on the endogenous construct. The effect sizes estimation by Cohen (1988) states that 0.02 represents a small effect, 0.15 represents a medium effect and 0.35 represents a large effect. Referring to Table 4, it can be seen that only six relationships showed an adequate $\mathrm{f}^{2}$ value with all relationships that have a small effect size. Although $\mathrm{H} 3$, $\mathrm{H} 4, \mathrm{H} 5$, and $\mathrm{H} 8$ showed a significant $p$ value, the $\mathrm{f}^{2}$ value demonstrated insubstantial estimations. Therefore, only six hypothesized relationships were supported which were H1, H2, H6, H7, H11, and H12.

\section{Significance of Group Differences}

Table 5 shows the summary of the multi group analysis (PLS-MGA) for the variables of self-perceived adult status and gender. The multigroup comparison was performed by using the bootstrapping procedure in order to determine the significance of group differences by observing the path coefficients and standard errors. Overall the PLS-MGA results indicated that not all hypothesized relationships differ significantly across the two groups of self-perceived adult status and gender. 







\section{FINDINGS AND DISCUSSION}

The aim of the present study is to examine the influence of peer attachment on the adjustment made by freshmen to life in the university. In the trust sub-scale, the findings show that only two of the hypotheses are supported. Trust has positively influenced both academic adjustment and social adjustment. This indicates that higher trust among peers will lead to higher academic and social adjustment. The findings of this research is consistent with Van Ingen, Freiheit, Steinfeldt, Moore, Wimer, Knutt, Scapinello, \& Roberts (2015) who found that peer trust was positively related to self-efficacy which, in turn was related to social skills and social competence. Tokuno (1983) pointed out that student life was a period of transition that students needed to resolve their issues with peers rather than with family members. Peer trust could help in preventing any stress experienced during the transition to university (Oswald \& Clark, 2003). Lunksy \& Benson (2001) also reported that individuals with strong peer trust would have higher social support, which in turn leads to a better quality of life. More than $90 \%$ of the respondents in the current study reported living outside of the family home; therefore, peers are the closest individuals during this period. The findings of the study also suggested that freshmen could benefit from the trust in their peers as this trust enhances their adjustment to life in the university, particularly in the academic and social context.

In the sub-scale of communication only one hypothesis was supported, meanwhile another hypothesis was not supported due to the different relationship. Peer communication has positively influenced social adjustment, but it has negatively influenced the personal-emotion adjustment. Similarly in the study by Van Ingen et al. (2015), such a negative relationship was also found, whereby peer communication was negatively related to social self-efficacy. Van Ingen et al. (2015) argued that the students were probably not using their communication skills effectively and there was a need for more research in this area. The current findings also reported a negative relationship between peer alienation and personalemotional adjustment that could justify the nuance and complexity of the peer communication construct. Another striking finding was the positive relationship between peer alienation and institutional attachment, therefore rejecting the hypothesis due to different 
relationship. There were no past literature to support this notion as this study is the first to examine the effect of peer alienation towards institutional attachment. Nevertheless, Zulkefly \& Wilkinson (2014) examined the psychometrics characteristics of IPPA among Malaysian adolescents and found that the original factors of IPPA did not show a replication towards Malaysian culture. They stated that "the understanding towards the attachment concept among young people in Malaysia is different. The nature of attachment in the Asian culture generally emphasized strongly on interdependence, socialization, in-group harmony in which causing the young people to supress their personal feelings and thoughts, as well as thinking about their behaviour based on other's thoughts, attitude, feelings, and action (p. 18). From the argument mentioned, it can be assumed that although the respondents feel alienated from their peers, they are actually wanted to be more attached towards their peers. Problems arised from the respondents themselves whereby they refused to share their personal feelings with their peers as a way of preventing any bad reaction from their peers. A further study need to be conducted to confirm this statement.

More research is needed to replicate the current study and as suggested by Gallarin \& Alonso-Arbiol (2013). Although the IPPA is a complete and adequate measure as a theoretical foundation for attachment theory, the structure factor is still ambiguous. Thus more research needed to conducted to evaluate the psychometric characteristics of IPPA especially the three factors (the correlation between peers communication and peers trust is very high in this study thus removing many items in order to fulfil the discriminant validity, and peer alienation factor somehow has different meaning in Asian culture). Past literature reported a mix finding of the psychometric properties of IPPA in different cultures and countries. Furthermore, studies done in Asia using the IPPA in examining attachment are usually unidimensional, without having the three subscales examined separately (Zulkefly, \& Wilkinson, 2014).

The multigroup moderation result also shows no significant difference for gender groups (male and female) and perceivedadult status groups (self-perceived adult and non-perceived adult) in the coefficients of peer attachment and adjustment to life in 
the university. The current findings are consistent with the results obtained in studies by Poyrazli, Arbona, Bullington, \& Pisecco (2001); Sümer et al. (2008); and Otlu (2010). These studies have all reported no gender differences on adjustment to life in the university. As for self-perceived adult status, the current study is consistent with Nelson (2009) and Rarick (2011). Although freshmen perceived that they had already reached adulthood, this in turn did not benefit their peer attachment and their adjustment to life in the university.

\section{IMPLICATIONS AND CONCLUSIONS}

The findings of this study seem to suggest several important implications. Firstly, the study has provided further corroborative evidence in support of the theory and literature. More specifically, it has empirically verified Howes and Spieker's (2008) argument regarding the combination of attachment theory and emerging adulthood theory as an alternate attachment bond during emerging adulthood period. In the current study, the factors that had influenced student adjustments to life in the university in the Malaysian context were examined. By adopting the framework of peer attachment and university adjustment, this study has shown that the hypothesized relationships were partially supported. In addition, following the suggestion made by Ishak, Yunus, and Iskandar (2010) and Zulkefly and Wilkinson (2014) regarding the limited literature exploring the attachment relationship among emerging adults in a non-western samples, this study has made an important empirical contribution to the literature on attachment, particularly in the context of freshmen in Malaysia.

Secondly, from the practical perspective, the findings of this study can be useful especially to counsellors and academicians who work with emerging adult clients in the Malaysian university setting. Counsellors could be trained to assist their emerging adult clients in fostering positive social supports especially with peers during the first year of life in the university. It is during this all important transition period that efforts to minimise peer alienation be carried out, since such alienation appeared to have the largest impact on university adjustment among Malaysian freshmen. Therefore, counsellors are 
encouraged to understand the complexity of the support system required for first year undergraduates, which would involve catering to the different freshmen needs and ensuring quality bonding in new friendships. Since the results showed that trust and communication were essential factors that positively impacted freshmen adjustment to life in the university, counsellors should be encouraged to use this knowledge and the necessary resources to address the factors which would enhance the development of peer support. Baptist, Norto, Adicco, Thompson, and Cook (2012) argued that the concept of emerging adulthood was still vague in Malaysia, therefore causing uncertainties in the acceptance and application of this concept. It is however, imperative that counsellors gain a better insight into Arnett's theory of emerging adult when working with their emerging adult clients (Lane, 2015). The subjective experience of emerging adulthood is different among emerging adults in different cultures and ethnic groups. As such when fostering emphatic understanding about the heterogeneity of emerging adulthood, it helps to understand the uniqueness of the transition process that was experienced particularly by first year university students.

To date, the literature regarding adjustment to life in the university was all from more than a decade old studies (Mohamed, 2012). Therefore, academicians could expand this area of study by embarking on new exploratory intitiatives such as was done in the present study. Future studies could further examine other transition-related adjustments to life after college or the transition from university to working life. Moreover, romantic partners were often discussed in the literature as important (Fraley \& Davis, 1997) as these partners could provide freshmen with significant emotional support (Weiss, 1974). Due to the unique functions of peer and romantic relationships to the adult in coping with a life in transition (Barry, Madsen, Nelson, Carroll, \& Badger, 2009), it is certainly very worthwhile to examine how attachment to romantic partners is differently linked with university adjustment among freshmen.

\section{REFERENCES}

Abdullah, M. C., Elias, H., Mahyuddin R., \& Uli, J. (2009). Adjustment amongst first year students in a Malaysian university. European Journal of Social Sciences, 8(3), 496-505. 
Abdullah, M. C., Kong, L. L., \& Talib, A. R. (2014). Perceived social support as predictor of university adjustment, and academic achievement amongst first year undergraduates in a Malaysian public unversity. Malaysian Journal of Learning and Instruction, 11, 59-73.

Ahmad, K., Fauziah, N., Azemi, Y., Shaari, M., \& Zailani, M. Y. (2002). Adjustment to college life and academic performance among Universiti Utara Malaysia Students (Unpublished Manuscript). Universiti Utara Malaysia, Kedah, Malaysia.

Ainsworth, M. D. S., Blehar, M. C., Waters, E., \& Wall, S. (1978). Patterns of attachment: A psychological study of the strange situation. Hillsdale, N.J.: Erlbaum.

Ariffin, A. A. M., Ahmad, A. H., Ahmad, S., \& Ibrahim, A. (2008). Determining decision-making styles and demographic differences in selecting higher education services among Malaysian. International Journal of Business and Society, 9(1).

Armsden, G. C., McCauley, E., Greenberg, M. T., Burke, P. M., \& Mitchell, J. R. (1990). Parent and peer attachment in early adolescent depression. Journal of Abnormal Child Psychology, 18(6), 683-697.

Armsden, G. C., \& Greenberg, M. T. (1987). The inventory of parent and peer attachment: Individual differences and their relationship to psychological well-being in adolescence. Journal of Youth and Adolescence, 16(5), 427-454.

Arnett, J. J. (2000). Emerging adulthood: A theory of development from the late teens through the twenties. American Psychologist, 55(5), 469.

Arnett, J. J. (2003). Conceptions of the transition to adulthood among emerging adults in American ethnic groups. In J. J. Arnett \& N. L. Galambos (Eds.). New directions for child and adolescent development: Exploring cultural conceptions of the transition to adulthood (pp. 63-75). San Francisco: Jossey-Bass.

Arnett, J. J. (2007). Emerging adulthood: What is it, and what is it good for? Child Development Perspectives, 1(2), 68-73.

Arnett, J. J. (2014). Emerging adulthood: The winding road from the late teens through the twenties (2nd ed.). Oxford: Oxford University Press. 
Bakar, A., \& Mohamed, S. (2004). Perceived leadership characteristics of students majoring in education at Universiti Putra Malaysia. Pertanika Journal of Social Sciences \& Humanities, 12(1), 45-52.

Bakar, N. H., Mohamed, Z., Abdullah, M. F. N. L., Yusof, S. I. M. (2015). Pembinaan model berstruktur penyesuaian akademik dalam kalangan pelajar. Journal of Human Capital Development, 8(1), 23-37.

Baker, R. W., \& Siryk, B. (1984). Measuring adjustment to college. Journal of Counseling Psychology, 31, 179-189.

Baker, R. W., \& Siryk, B. (1989). Manual for student adaptation to college questionnaire. Los Angeles: Western Psychological Services.

Barry, C. M., Madsen, S. D., Nelson, L. J., Carroll, J. S., \& Badger, S. (2009). Friendship and romantic relationship qualities in emerging adulthood: Differential associations with identity development and achieved adulthood criteria. Journal of Adult Development, 16(4), 209-222.

Beyers, W., \& Goossens, L. (2008). Dynamics of perceived parenting and identity formation in late adolescence. Journal of Adolescence, 31(2), 165-184.

Blinn-Pike, L., Worthy, S. L., Jonkman, J. N., \& Smith, G. R. (2008). Emerging adult versus adult status among college students: Examination of explanatory variables. Adolescence, 43(171), 577.

Bloom, M. (1980). Adolescent-parental separation. Gardner Press: New York.

Bowlby, J. (1969). Attachment and loss. Vol. 1. Attachment, Basic, New York.

Byrd, K. L., \& MacDonald, G. (2005). Defining college readiness from the inside out: First-generation college student perspectives. Community College Review, 33(1), 22-37.

Chickering, A. W. (1969). Education and identity. Jossey-Bass.

Ciarrochi, J., \& Scott, G. (2006). The link between emotional competence and well-being: A longitudinal study. British Journal of Guidance \& Counselling, 34(2), 231-243.

Cohen, J. (1988). Statistical power analysis for the behavioral sciences (2nd ed.). Hilllsdale, NJ: Lawrence Erlbaum Associates, Inc. 
Collins, W. A., \& van Dulmen, M. (2006). The significance of middle childhood peer competence for work and relationships in early adulthood. Developmental Contexts in Middle Childhood: Bridges to Adolescence and Adulthood, 23-40.

Montgomery, M. J., \& Côté, J. E. (2003). College as a transition to adulthood. Blackwell Handbook of Adolescence, 149-172.

Davis, E. R. (2012). The effect of parental attachment and level of perceived stress on college adjustment in first year college students (Unpublished doctoral dissertation). Alliant International University.

Diamond, L. M., Fagundes, C. P., \& Butterworth, M. R. (2010). Intimate relationships across the lifespan. In M. E. Lamb, L. White, \& A. Freund (Eds.), Handbook of lifespan development (Vol. 2, pp. 379-433). New York, NY: John Wiley.

Dixon, S. K., \& Kurpius, S. E. R. (2008). Depression and college stress among university undergraduates: Do mattering and self-esteem make a difference?.Journal of College Student Development, 49(5), 412-424.

Doherty, N. A., \& Feeney, J. A. (2004). The composition of attachment networks throughout the adult years. Personal Relationships, 11(4), 469-488.

Duchesne, S., Ratelle, C. F., Larose, S., \& Guay, F. (2007). Adjustment trajectories in college science programs: Perceptions of qualities of parents' and college teachers' relationships. Journal of Counseling Psychology, 54(1), 62.

Dyson, R., \& Renk, K. (2006). Freshmen adaptation to university life: Depressive symptoms, stress, and coping. Journal of Clinical Psychology, 62(10), 1231-1244.

Eimers, M. T., \& Pike, G. R. (1997). Minority and nonminority adjustment to college: Differences or similarities?. Research in Higher Education, 38(1), 77-97.

Erikson, E. H. (1963). Youth: Change and challenge. New York: Basic Books.

Feldt, R. C., Graham, M., \& Dew, D. (2011). Measuring adjustment to college: Construct validity of the student adaptation to college questionnaire.Measurement and Evaluation in Counseling and Development, 44(2), 92-104.

Fornell, C., \& Larcker, D. F. (1981). Evaluating structural equation models with unobservable variables and measurement error. Journal of Marketing Research, 39-50. 
Fraley, R. C., \& Davis, K. E. (1997). Attachment formation and transfer in young adults' close friendships and romantic relationships. Personal relationships, 4(2), 131-144.

Friedlander, L. J., Reid, G. J., Shupak, N., \& Cribbie, R. (2007). Social support, self-esteem, and stress as predictors of adjustment to university among first-year undergraduates. Journal of College Student Development, 48(3), 259-274.

Gallarin, M., \& Alonso-Arbiol, I. (2013). Dimensionality of the Inventory of Parent and Peer Attachment: Evaluation with the Spanish Version. The Spanish journal of psychology, 16, E55.

Gray, R., Vitak, J., Easton, E. W., \& Ellison, N. B. (2013). Examining social adjustment to college in the age of social media: Factors influencing successful transitions and persistence. Computers \& Education, 67, 193-207.

Gerdes, H., \& Mallinckrodt, B. (1994). Emotional, social, and academic adjustment of college students: A longitudinal study of retention. Journal of Counseling \& Development, 72(3), 281-288.

Goodboy, A. K., Martin, M. M., \& Goldman, Z. W. (2015). Students' experiences of bullying in high school and their adjustment and motivation during the first semester of college. Western Journal of Communication, 1-19.

Gorrese, A. (2015). Peer Attachment and Youth Internalizing Problems: A Meta-Analysis. In Child \& Youth Care Forum (pp. 1-28). Springer US.

Gorrese, A., \& Ruggieri, R. (2012). Peer attachment: A meta-analytic review of gender and age differences and associations with parent attachment. Journal of youth and adolescence, 41(5), 650-672.

Hair, J. F., Hult, G. T. M., Ringle, C., \& Sarstedt, M. (2014). A primer on partial least squares structural equation modeling (PLS-SEM). Sage Publications.

Hiester, M., Nordstrom, A., \& Swenson, L. M. (2009). Stability and change in parental attachment and adjustment outcomes during the first semester transition to college life. Journal of College Student Development, 50(5), 521-538.

Holt, L. J. (2014). Attitudes about help-seeking mediate the relation between parent attachment and academic adjustment in first-year college students. Journal of College Student Development, 55(4), 418-423. 
Howes, C., \& Spieker, S. (2008). Attachment relationships in the context of multiple caregivers. In J. Cassidy \& PR Shaver (Eds.), Handbook of attachment: Theory, research and clinical applications (pp. 317-332).

Ishak, N. M., Yunus, M. M., \& Iskandar, I. P. (2010). Trust, communication and healthy parental attachment among Malaysian academically talented college students. ProcediaSocial and Behavioral Sciences, 9, 1529-1536.

Janković, B., Nikolić, M., Vukonjanski, J., \& Terek, E. (2016). The impact of Facebook and smart phone usage on the leisure activities and college adjustment of students in Serbia. Computers in Human Behavior, 55, 354-363.

Karahan, F., Sardoğan, M. E., Özkamalı, E., \& Dicle, A. N. (2005). Üniversite 1. sınıf öğrencilerinin üniversiteye uyum düzeylerinin sosyokültürel etkinlikler açısından incelenmesi. Çukurova Üniversitesi Ĕ̈itim Fakültesi Dergisi, 2(30), 63-72.

Kenny, M. E., \& Donaldson, G. A. (1991). Contributions of parental attachment and family structure to the social and psychological functioning of first-year college students. Journal of Counseling Psychology, 38(4), 479.

Laible, D. J., Carlo, G., \& Raffaelli, M. (2000). The differential relations of parent and peer attachment to adolescent adjustment. Journal of Youth and Adolescence, 29(1), 45-59.

Lane, J. A. (2015). Counseling emerging adults in transition: Practical applications of attachment and social support research. The Professional Counselor, 5(1), 15-27.

Lapsley, D. K., \& Edgerton, J. (2002). Separation-individuation, adult attachment style, and college adjustment. Journal of Counseling \& Development, 80(4), 484-492.

Lapsley, D. K., Rice, K. G., \& FitzGerald, D. P. (1990). Adolescent attachment, identity, and adjustment to college: Implications for the continuity of adaptation hypothesis. Journal of Counseling \& Development, 68(5), 561-565.

Lenz, A. S. (2014). Mediating Effects of Relationships With Mentors on College Adjustment. Journal of College Counseling, 17(3), 195-207.

Love, K., Tyler, K., Thomas, D., Garriott, P., Brown, C., \& RoanBelle, C. (2009). Influence of multiple attachments on wellbeing: A model for African Americans attending historically 
black colleges and universities. Journal of Diversity in Higher Education, 2(1), 35.

Lunsky, Y., \& Benson, B. A. (2001). Association between perceived social support and strain, and positive and negative outcome for adults with mild intellectual disability. Journal of Intellectual Disability Research, 45(2), 106-114.

Martínez-López, Z., Fernández, M. F. P., Couñago, M. A. G., Vacas, C. T., daSilva Almeida, L., \& González, M.S. R. (2014). Apoyo social en universitarios españoles de primer año: propiedades psicométricas del Social Support Questionnaire-Short Form y el Social Provisions Scale. Revista Latinoamericana de Psicología, 46(2), 102-110.

Mattanah, J. F., Lopez, F. G., \& Govern, J. M. (2011). The contributions of parental attachment bonds to college student development and adjustment: a meta-analytic review. Journal of Counseling Psychology, 58(4), 565.

Mayselessx, O. (2004). Home leaving to military service attachment concerns, transfer of attachment functions from parents to peers, and adjustment. Journal of Adolescent Research, 19(5), 533-558.

Meckelmann, V., \& Peiker, P. (2013). Development in emerging adulthood-comparison of employed and unemployed emerging adults in Germany. In Poster presentation at the 6th Conference on Emerging Adulthood, Chicago, IL.

Melendez, M. C. (2015). Adjustment to college in an urban commuter setting the impact of gender, race/ethnicity, and athletic participation. Journal of College Student Retention: Research, Theory \& Practice. doi: 1521025115579671.

Ministry of Education Malaysia (2013). Indikator pengajian tinggi Malaysia 2013. Retrieved from http://www.mohe.gov.my/ web_statistik/Indikator_Pengajian_Tinggi_Malaysia_2013. pdf

Mohamed, N. (2012). Adjustment to University: Predictors, Outcomes and Trajectories (Unpublisded doctoral dissertation). University of Central Lancashire.

Nakayama, R., Nakanishi, Y., Nagahama, F., \& Nakajima, M. (2015). Interpersonal motivation in a first year experience class influences freshmen's university adjustment. Shinrigaku kenkyu: The Japanese journal of psychology, 86(2), 170-176. 
Nelson, L. J. (2009). An examination of emerging adulthood in Romanian college students. International Journal of Behavioral Development, 33(5), 402-411.

Nelson, L. J., xing Duan, X., Padilla-Walker, L. M., \& Luster, S. S. (2012). Facing adulthood: Comparing the criteria that Chinese emerging adults and their parents have for adulthood. Journal of Adolescent Research, 0743558412467685.

Nelson, L. J., \& Barry, C. M. (2005). Distinguishing features of emerging adulthood the role of self-classification as an adult. Journal of Adolescent Research, 20(2), 242-262.

Nolan, A. M. (2006). An examination of features of emerging adulthood (Unpublished doctoral dissertation). Carleton University.

Oswald, D. L., \& Clark, E. M. (2003). Best friends forever?: High school best friendships and the transition to college. Personal Relationships, 10(2), 187-196.

Otlu, F. N. (2010). College adjustment of international students: the role of gender, acculturative stress, coping skills, cultural distance, and perceived social support. Ankara, Turkey. A thesis submitted to Middle East Technical University.

Pancer, S. M., Hunsberger, B., Pratt, M. W., \& Alisat, S. (2000). Cognitive complexity of expectations and adjustment to university in the first year. Journal of Adolescent Research, 15(1), 38-57.

Parker, J.D., Summerfeldt, L. J., Hogan, M. J., \& Majeski, S. A. (2004). Emotional intelligence and academic success: Examining the transition from high school to university. Personality and individual differences, 36(1), 163-172.

Pascarella, E. T., \& Terenzini, P. T. (1980). Predicting freshman persistence and voluntary dropout decisions from a theoretical model. The Journal of Higher Education, 60-75.

Poyrazli, S., Arbona, C., Bullington, R., \& Pisecco, S. (2001). Adjustment issues of Turkish college students studying in the United States. College Student Journal.

Ramler, T. R., Tennison, L. R., Lynch, J., \& Murphy, P. (2015). Mindfulness and the college transition: The efficacy of an adapted mindfulness-based stress reduction intervention in fostering adjustment amongfirst-year students. Mindfulness, $1-10$. 
Rarick, T. M. (2011). Importance of perceived adulthood and goal pursuit in emerging adult college students. America (Unpublished doctoral dissertation). Kansas State University. Redhwan, A. A. N., Sami, A. R., Karim, A., Chan, R., \& Zaleha, M. (2009). Stress and coping strategies among Management and Science University students: A qualitative study. The International Medical Journal of Malaysia,8(2).

Ringle, C. M., Wende, S., \& Will, A. (2005). SmartPLS 2.0 [Computer software]. Retrieved from www.smartpls.de

Sarigiani, P., Trumbell, J., \& Camarena, P. (2013). Electronic communications technologies and the transition to college: Links to parent-child attachment and adjustment. Journal of The First-Year Experience \& Students in Transition,25(1), 35-60.

Schnyders, C. (2012). Parental and peer attachment as predictors of the perceived experience of emerging adulthood among undergraduates between the ages of 18-20: A multiple Regression Study (Unpublished doctoral dissertation). Kent State University.

Seidman, E., \& French, S. E. (2004). Developmental trajectories and ecological transitions: A two-step procedure to aid in the choice of prevention and promotion interventions. Development and Psychopathology, 16(04), 1141-1159.

Selby, J. C. (2001). The relationship of parental attachment, peer attachment, and self-concept to the adjustment of firstyear college students. (Unpublished doctoral dissertation). University of North Texas).

Siah, P. C., \& Tan, S. H. (2015). Motivational orientation, perceived stress and university adjustment among first year undergraduates in Malaysia. Journal of Institutional Research South East Asia, 13(1), 19-29.

Schultheiss, D. E. P., \& Blustein, D. L. (1994). Role of adolescentparent relationships in college student development and adjustment. Journal of Counseling Psychology, 41(2), 248.

Schulenberg, J. E., \& Zarrett, N. R. (2006). Mental health during emerging adulthood: Continuity and discontinuity in courses, causes, and functions. In J. J. Arnett \& J. L. Tanner (Eds.). Emerging adults in America: Coming of age in the 21st century. (pp. 135-172). Washington, DC: APA Books. 
Smojver-Ažić, S., Martinac Dorčić, T., \& Živčić-Bećirević, I. (2015). Attachment to Parents and Depressive Symptoms in College Students: The Mediating Role of Initial Emotional Adjustment and Psychological Needs. Psychological Topics, 24(1), 135-153.

Sullivan, G. M., \& Feinn, R. (2012). Using effect size-or why the $\mathrm{P}$ value is not enough. Journal of graduate medical education, 4(3), 279-282.

Sümer, S., Poyrazli, S., \& Grahame, K. (2008). Predictors of depression and anxiety among international students. Journal of Counseling \& Development,86(4), 429-437.

Tanner, J. L. (2006). Recentering during emerging adulthood: A critical turning point in life span human development. In J. J. Arnett \& J. L. Tanner (Eds.), Emerging adults in America: Coming of age in the 21 st century (pp. 21-55). Washington, DC: APA Books.

Tinto, V. (1987). Leaving college: Rethinking the causes and cures of student attrition. University of Chicago Press, 5801 S. Ellis Avenue, Chicago, IL 60637.

Tinto, V. (1996). Reconstructing the first year of college. Planning for Higher Education, 25(1), 1-6.

Tokuno, K. A. (1983). Friendship and transition in early adulthood. The Journal of genetic psychology, 143(2), 207-216.

Torres, J. B., \& Solberg, V. S. (2001). Role of self-efficacy, stress, social integration, and family support in Latino college student persistence and health. Journal of vocational behavior, 59(1), 53-63.

van Ingen, D. J., Freiheit, S. R., Steinfeldt, J. A., Moore, L. L., Wimer, D. J., Knutt, A. D., Scapinello, S, \& Roberts, A. (2015). Helicopter parenting: The Eeffect of an overbearing caregiving style on peer attachment and self-efficacy. Journal of College Counseling, 18(1), 7-20.

Waller, T. O. (2009). A mixed method approach for assessing the adjustment of incoming first-year students in a summer bridge program (Unpublished doctoral dissertation). Virginia Polytechnic Institute and State University.

Wang, A., Chen, L., Zhao, B., \& Xu, Y. (2006). First-year Students' psychological and behavior adaptation to college: The role of coping strategies and social support. Online Submission, 3(5), 51-57. 
Weckwerth, A. C., \& Flynn, D. M. (2006). Effect of sex on perceived support and burnout in university students. College Student Journal, 40(2), 237.

Weidman, J. C. (1989). Undergraduate socialization: A conceptual approach. In Higher education: Handbook of theory and research (pp. 289-322). Agathon Press.

Weiss, R. S. (1974). The provisions of social relationships. In Z. Rubin (Ed.), Doing unto others (pp. 17-26). Englewood Cliffs, NJ: Prentice-Hall.

Wider, W., Halik, M., Mustapha, M. \& Bahari, F. (2015). A preliminary analysis of the perceptions of the five features of emerging adulthood: A comparison of perceived adult status among emerging adults in Malaysia. Projournal of Humanities and Social Science, 3(1), 12-24.

Wilkinson, R. B. (2006). Age and sex differences in the influence of attachment relationships on adolescent psychological health. The Australian Educational and Developmental Psychologist, 23(02), 87-104.

Wintre, M. G., \& Yaffe, M. (2000). First-year students' adjustment to university life as a function of relationships with parents. Journal of Adolescent Research, 15(1), 9-37.

Yalim, D. (2007). First year college adjustment: The role of coping, ego-resiliency, optimism and gender (Unpublished doctoral dissertation). Middle East Technical University.

Yang, C. C., \& Brown, B. B. (2016). Online self-presentation on facebook and self development during the college transition. Journal of Youth and Adolescence, 45(2), 402-416.

Yazedjian, A., Toews, M. L., \& Navarro, A. (2009). Exploring parental factors, adjustment, and academic achievement among White and Hispanic college students. Journal of college student development, 50(4), 458-467.

Zulkefly, N. S., \& Wilkinson, R. B. (2014). Measuring specific attachment relationships of mother, father and peer in Malaysian adolescents. Child Indicators Research, 1-22. 